\title{
NOTICIAS REFERENTES AL PASO DE ALGUNOS PINTORES A LA NUEVA ESPAÑA ${ }^{1}$
}

\author{
José Rogelio Ruiz Gomar C.
}

En los ricos fondos documentales que se guardan en el Archivo General de Indias, en la ciudad de Sevilla, España, siempre hay forma de extraer noticias que pueden ser útiles a los estudiosos atentos al desarrollo de las artes en los vastos territorios sobre los que España tuvo dominio en este lado del océano.

Mi propósito en estas líneas es el de dar a conocer algunos datos recolectados en tan importante acervo, suceptibles de enriquecer el conocimiento que tenemos de la pintura realizada en el ámbito de la Nueva España, por cuanto que se trata de noticias reunidas en relación al paso hacia dicho virreinato de valiosos pintores: los españoles Andrés de la Concha, Alonso Franco, Alonso Vázquez y Pedro García Ferrer, y el flamenco Diego de Borgraf, quienes, al avecindarse entre nosotros, habrian de contribuir, cual más cual menos, a la formación y lustre de la escuela pictórica novohispana.

Para mediados del siglo xvi la colonización de la Nueva España se antojaba casi un hecho consumado. Cierto que aún faltaban tierras por explorar y domeñar, pero gradualmente las gentes que habian pasado a estas latitudes en pos de riqueza y aventura se empezaban a sentir con apego a la nueva tierrà. Los cruentos y difíciles años de la conquista habían quedado atrás y se respiraban aires cada rez más sosegados. Una nueva generación iba cobrando forma, acaso menos épica y vigorosa, pero más refinada.

Trasladado esto al campo de las artes se traduce en el hecho de que debieron de ser pocos los artistas -españoles o europeo en general- que en fechas tempranas estuvieran dispuestos a abandonar y cambiar el medio en el que se desenvolvían, con una clientela que mal que bien sabía remunerar sus creaciones, por el ignoto mundo americano, aún pobre y en gestación. Conforme avanzaba el siglo, sin embargo, la progresiva consolidación que en todos los órdenes se empezó a vivir, hizo posible la floración de un mercado artístico de cierta importancia que no tardó en resultar atractivo para los artistas del viejo mundo, hasta

1 Estas notas son el fruto de la investigación que llevé a cabo en el Archivo General de Indias, merced a una beca otorgada por el Instituto de Cooperación Iberoamericana y a la comisión que para dicho fin me fue concedida por el Instituto de Investigaciones Estéticas. Quede aquí constancia de mi reconocimiento. 
el grado de incitarles a enviar sus obras o, mejor aún, a emprender el largo viaje hacia este nuevo mundo que prometía, ahora sí, un campo amplio y seguro para el ejercicio de los más variados oficios.

Es obvio que para cada caso debió de ser diferente la motivación, diverso el incentivo que les animara a cruzar el Atlántico; pero cábe afirmar que en algunos de ellos fue decisiva la invitación formulada por quienes habrían de pasar al nuevo mundo investidos con los altos cargos de virrey o de arzobispo; de tal suerte que es relativamente frecuente el encontrarlos adscritos como criados en los séquitos de dichos personajes. Baste mencionar que en 1566 el virrey Gastón de Peralta, marqués de Falces, trajo consigo al flamenco Simón Pereyns; en 1603 el marqués de Montes Claros haría lo propio con Alonso Vázquez, y el obispo Palafox otro tanto en 1640 con Pedro García Ferrer y Diego de Borgraf.

Advirtamos, finalmente, que el fenómeno del paso de artistas y la remesa de obras de arte al nuevo mundo aún lo encontramos funcionando para la centuria decimoséptima, si bien en escala cada vez menor, al menos por lo que respecta al virreinato de la Nueva España. ${ }^{2}$

Empecemos con el caso del célebre sevillano Andrés de la Concha. Ya don Enrique Marco Dorta publicó las noticias referentes a su paso, ${ }^{\mathbf{3}}$ de suerte que si lo traigo nuevamente a colación es tan sólo con el ánimo de precisar algunos puntos.

De acuerdo a los registros, la licencia que le concedió el Consejo de Indias era para pasar (junto con Luis de Campuzano y Francisco de Piqueras) a la isla de Santo Domingo en calidad de criado de fray Agustín de Campuzano y de los 24 religiosos dominicos que con él venían; la fecha de dicha licencia fue la del 19 de febrero de $1568 .{ }^{4}$

Me apresuro a externar mi opinión de que la credibilidad de estas noticias no invalidan el sentir general de que pasaba Concha contratado por Gonzalo de las Casas para ejecutar el retablo de la iglesia del convento dominico de Yanhuitlán, en Oaxaca, por cuanto que es perfectamente válido el suponer que después de una breve estancia en la isla

2 En buena medida ello obedece al hecho de que para la segunda mitad del siglo xvu los talleres novohispanos habrian de alcanzar tal grado de desarrollo e importancia que fueron capaces de satisfacer con su producción los requerimientos artísticos de la sociedad local, en la cual y para la cual trabajaban, hasta el punto de hacer prácticamente innecesario tanto el paso de!artistas como la importación de obras.

3 Enrique Marco Dorta, "Noticias sobre el pintor Andxés de Concha", Archivo Español de Arte, v. I, núm. 199, Madrid, julio-septiembre, 1977, p. 343.

4 Véase: Documento : 1 . 
de Santo Domingo -en el caso de que efectivamente hubiera arribado primero a ella- continuara su viaje hacia la Nueva España, en donde ciertamente habría de trabajar asiduamente y ejecutar valiosa obra en campos tan diversos como la pintura, el dorado, la escultura y la arquitectura. $^{5}$

Vengamos ahora con Alonso Franco. Este artista era natural de la villa de Yllescas, Toledo y su prestigio no debió de ser poco entre sus contemporáneos, ya que es mencionado por Bernardo de Balbuena y Arias de Villalobos. Acaso fue padre del conocido cronista de la orden de Santo Domingo del mismo nombre.

Su licencia para salir de España le fue extendida el 26 de noviembre de 1580; ${ }^{6}$ a través de ella nos enteramos que fueron sus padres Diego Franco y María Fernández y que su destino era el deslumbrante reino de la China, por cuanto que, en su calidad de pintor, debia formar parte de una ambiciosa embajada de carácter diplomático, misionero y cultural que se organizaba para enviarle presentes al rey de tan lejanas tierras. ${ }^{7}$ Mas, como dicha embajada no se llevó a cabo, Franco terminó, seguramente, por avecindarse en la Nueva España. Para efecto de tal viaje Franco se vio precisado a pagar una fianza que garantizara su regreso a España, retorno temporal que quizá sea al que alude Martín Soria hacia $1588 .{ }^{8}$

5 Vid. Guillermo Tovar de Teresa, Pintura y escultura del Renacimiento en México, México, INAH, 1979, y Martha Fernández, Arquitectura y gobierno virreinal. Los maestros mayores'de la ciudad de México. Siglo XVII, México, IIE (en prensa).

6 Véase: Documento 2.

7 Esta expedición fue propuesta al rey de España hacia 1575 por el agustino fray Diego de Herrera y otros religiosos de la misma orden. Entre los obsequios que se enviaban se enumeran varios y curiosos relojes, valuados en 199,700 maravedíes, a cargo de los cuales iría Juan Guzmán, relojero natural de Villalón, y cuatro lienzos al óleo ejecutados por Alonso Sánchez Coello "criado de S. M. y su pintor", valuados en 400 ducados: "el uno de una imagen de Nuestra Señora de la Concepción, otro de un retrato del Emperador Nuestro señor que está en gloria, puesto a caballo, y los otros dos lienzos de dos retratos de S. M. [seguramente de Felipe II], el uno puesto a caballo y el otro a pie”. A. G. I. Indiferente General 426, f. 211 - 213. Debo estas noticias a la gentileza de la doctora Juana Gil-Bermejo, y le agradezco, asimismo, el haberme llamado la atención sobre dichos lienzos que, como ella supone, al no llegar a su destino, debieron quedar engalanando el Palacio de los Virreyes en México, especialmente por lo que toca al "retrato del Emperador.. " puesto a caballo", que muy probablemente no sea otro que el que aún alcanzó a ver Isidro Sariñana (Llanto de Occidente) y que se perdió en el incendio de 1692; retrato que, de ser el mismo, es de Sánchez Coello y no, como hasta ahora se pensaba, de mano de Tiziano

8 George Kubler y Martin Soria, Art and Architecture in Spain, and Portugal and 
Por lo que toca al paso a México del prestigioso artista andaluz Alonso Vázquez creo estar en condiciones de confirmar que efectivamente se verificó en el año de 1603 dentro del séquito del marqués de Montes Claros, tal y como se venía concediendo en base a inferencias indirectas. ${ }^{9}$ En efecto, el nombre de este enigmático pintor, quien tras exitosa carrera en Sevilla y sus alrededores quiso probar fortuna en la Nueva España, aparece asentado en una lista de criados que en ese año de 1603 venían al servicio del mencionado virrey, ${ }^{10}$ en la flota que ese año hacía carrera a las Indias, comandada por el general don Fulgencio de Meneses y Toledo (quien habría de morir a poco de llagar a Veracruz).

Debo advertir que la relación a que aludo fue levantada el 20 de julio de ese año en alta mar y corresponde a los criados que venían embarcados en la nao almiranta; la de los que venían en la nao capitana fue levantada dos días después. ${ }^{11}$ La razón de que se haya levantado en alta mar obedece a que fue preciso acelerar la salida de la flota por las condiciones del tiempo, y obviamente ello impidió que se practicara con el rigor acostumbrado el registro de las gentes que acompañaban al virrey. Lamentable circunstancia que nos privó de una magnífica ocasión de poder conocer datos nuevos sobre este artista, de quien contamos con muy escasas noticias; toda vez que mientras lo usual en

their American dominions. 1500-1800, Londres, 1959, segunda parte, p. 307 y 392 (nota 24).

${ }^{9}$ No es el momento aqui de hacer una revisión pormenotizada de los planteamientos en torno a este punto, pero sí juzgo necesario dar una síntesis de los mismos: se conjugaban, por un lado, los hechos de que en ese año Vázquez dejaba en Sevilla un cuadro sin concluir, y de que justo por esas fechas aparecían en México; y, pox el otro, se tenía el dato de que en ese mismo año y precisamente hacia la Nueva España se trasladaba don Juan de Mendoza y Luna para hacerse cargo de la administración de dicho virreinato. Al unir estos datos la conclusión caía por su propio peso; faltaba sólo probarla documentalmente. Vid. José Rogelio Ruiz Gomar, "El paso de Alonso Vázquez a la Nueva España". (Trabajo presentado en las IIL Jornadas de Andalucia y América, La Rábida, España, marzo de 1983; en prensa.)

10 Véase: Documento 3. Cabe apuntar que dicho virrey podía pasar hasta 70 criados a su servicio, pero al salir de Cádiz sólo traía 50 , incluidos 4 esclavos y 1 as 8 doncellas que acompañaban a doña Ana Mensia de Mendoza, su mujer.

11 Hay una primera lista de los que supuestamente debian venir en la nao almiranta, datada en Sevilla el 14 de julio de ese año (A. G. I. Contratación 2974; hoja suelta con la anotación marginal de: "La fianza que otorgó Diego López Dória del flete de los criados del virrey y de alguna ropa") en que no figura el nombre de Vázquez; pero como en el cotejo de las dos listas se detectan varias omisiones más y algunas variantes, cabe pensar que tales ixtegularidades fuesen imputables a ta premura que rodeó los preparativos y trámites generales de la mencionada flota. 
tales registros - con todo lo escuetos que son- es que se consignen datos importantes, como pueden ser el lugar de nacimiento, nombre de los padres, edad, estado civil y con suerte una somera descripción física de los interesados, en esta ocasión nos tenemos que conformar con el simple enlistado de su nombre. ${ }^{12}$

Por último, Pedro García Ferrer y el flamenco Diego Borgraf se despacharon a Nueva España por criados del obispo de Puebla Juan de Palafox y Mendoza en: 1640.

En lo que respecta a García Ferrer podemos decir que este dato era de sobra conocido, pero hasta donde sé no se había confirmado documentalmente. En cambio el que Borgraf haya llegado igualmente con el controvertido obispo es noticia que hasta ahora se ignoraba. ${ }^{13}$

En los registros respectivos García Ferrer declaró tener 40 años y se le describe "barbirrubio, con una señal de herida en el rostro, debajo de la boca". Por su parte Borgraf (a quien se le nombra Diego "Burclab") dijo tener sólo 18 años, y se le describe de "barba hendida, blanco y bajo y abultado de rostro". Con base a la edad declarada cabría suponer que venía como aprendiz de García Ferrer. Además, en su cali. dad de flamenco, requirió de licencia expresa del rey. ${ }^{14}$

Por considerar que las noticias aquí vertidas pudieran ser de interés a los especialistas, es que las doy a conocer. La contribución es modesta, pero nunca será suficiente el insistir que muchas noticias del mismo tenor o de índole diversa, pero igualmente útiles y valiosas, aún permanecen entre los gruesos expedientes del prestigioso archivo, en espera del paciente investigador que las saque a la luz Es en este sentido que espero no pase mucho tiempo para que podamos contar con información más precisa y completa sobre los numerosos artistas que pasaron a la Nueva España, y se llenen los vacíos de información que no han

12 Como en ningún momento se epecifica que fuese pintor, cabe la posibilidad de que se trate de un homónimo; posibilidad que no debe descartarse, aun cuando me inclino a suponer que no es otro que nuestro Alonso Vázquez.

13 Ya Francisco Pérez Salazar (Historia de la pintura en Puebla, México, IIE, 1962, p 222, nota 15) ponía en duda la afirmación de que hubiese venido a México con el marqués de Gelves en 1621 -como había sostenido Eduardo Gómez Haro en El Nacional, México, 8 de mayo de 1917-, y suponía que para antes del ańo de 1649 aún no llegaba a la ciudad de Puebla "porque en la catedral angelopolitana no se encuentra nada suyo, anterior a la consagración" y a que justo en ese año se tenía el primer dato suyo conocido al recibir tres aprendices (Ibid, pp, 68-69). Para más noticias en relación a García Ferrer y a Borgraf, véanse los interesantes documentos y observaciones que sobre ellos publica este mismo autor.

14 Véase: Documento 4 
podido ser satisfechos, como son los casos del vasco Baltasar de Echave (Orio) y de Sebastián López de Arteaga, por no citar sino a los más urgentes. ${ }^{15}$

\section{DOGUMENTOS}

\section{DOCUMENTO 1}

A. G. I Contratación: 5537. "Asiento de pasajeros a Indias". Libro III. Año 1568, f. 269.

19 de febrero.

no 411 Luis Campuzano, natural de Guadalajara, hijo del capitán Gutierre de Campuzano y de doña Marqués de Ribera

no 412 Andrés de la Concha, natural de Sevilla, hijo de Francisco de Concha y de Isabel Sánchez

nọ 413 Francisco de Piqueras, natural de Alcalá del Río, hijo de Pedro Piqueras y de Magdalena Cebriana

Y los susodichos se despacharon a la isla de Santo Domingo por solteros y por criados de fray Agustín Campuzano y de los veinte y cuatro religiosos dominicos que lleva por cédula de Su Majestad.

\section{DOCUMENTO 2}

A. G. I. Contratación: 5538. "Asiento de pasajeros a Indias". Año 1580, f. 207 v. $(362$ v. $)$

26 de noviembre

no 725 Alonso Franco, pintor, natural de la villa de Yllescas, hijo de Diego Franco y de María Fernández, se despachó a la China, por soltero y para tener cuenta con las pinturas que se envían al rey de la China por cédula de $\mathrm{Su}$

Majestad en la nao maestre; y el dicho Alonso Franco dio fianzas en la cantidad de 100 mil maravedíes de ir a la dicha provincia de la China.

\section{DOCUMENTO 3}

A. G. I. Contratación: 5273. "Información y licencias de pasajeros". Año 1603. Ramo 3: Visita de los criados y ropa del marqués de Montes Claros, virrey

15 Aunque mi interés se ha centrado en los pintores, aprovecho para llamar la atención sobre el hecho de que el 23 de mayo de 1577 se asienta el paso a la Nueva España de un tal Pedro de Requena, quien acaso resulte ser el correcto escultor elogiado por Arias de Villalobos y autor de la estatuaria del retablo de Huejotzingo. Vid Luis Romera Iruela y María del Carmen Galbis, Catálogo de pasajeros a Indias, v. v, t. I, Madrid, 1980, p. 647, núm. 4449. 
de la Nueva España. (Con otra grafía y tinta:) Don Juan de Mendoza y Luna, marqués de Montes Claros, virrey de la Nueva España y los criados, así solteros como casados, que llevó consigo con licencia a dicha provincia.

(Al margen:) Visita de los criados del señor marqués de Montes Claros de la nao almiranta.

En la mar, en la nao almiranta, en veinte días del mes de julio de 1609 años, el señor Pedro Vázquez de Vitoria, almirante de la flota y armada que va a la provincia de Nueva España, de que es capitán general señor Don Fulgencio de Meneses y Toledo, por instrucción suya se visitó en la nao almiranta de la dicha flota la gente y criados que en ella lleva el señor marqués de Montes Claros, en presencia de mí el presente escribano, que es la siguiente

- Don Juan de Guzmán

- Sebastián de Cetina

- Don Alonso Mejía

- Don Juan de Rucavado

- Rodrigo de Bilbao, la vieja

- Don Alonso Laso

-- Don Gabriel Suárez

- Don Francisco de Santillana

- Don Juan Bohorquez

- Don Juan de Saavedra

- Don Antonio de Ayala

- Don Nicolás de Melgoso

- Don Juan Gaytán

- Don Manuel de Arellano

- Don Gabriel de Tamayo

- Don Gabriel de Ávila

- Don Gacía de Paredes

- Don Cristóbal de Arellano

- Don Miguel de Castro

-- Juan Bautista Sánchez de Salazar

- ALONSO VÁZQUEZ

- Miguel de Rojas

- Martín de Sigurola

- Diego de Rojas

Todas las cuales dichas personas se visitaron en esta dicha nao almiranta por el señor almirante en presencia de mi, el presente escribano mayor, por criados del dicho marqués virrey de la Nueva España, y para que de ello conste di este testimonio en la mar, fecho ut supra " (Rúbricas:) Pedro Vázquez de Vitoria; Miguel Dantes (escribano mayor). 


\section{DOCUMENTO 4}

A. G. I. Contratación: 5539. Libro 5. "Lista de pasajeros. 1625-1660”. f. §96 17 de marzo de 1640

- Pedro Garcia Ferrer, natural de Alcoriza, diócesis de Zaragoza.

- Diego Burclab (sic), flamenco, natural de Brabante, diócesis de Amberes. Las cuales dichas personas se despacharon por criados del señor licenciado Don Juan de Palafox y Mendoza, obispo de la iglesia catedral de la Puebla de los Ángeles, en la nao almiranta de la flota, por cédula de S. M . . .

A. G. I. Contratación: 5422. "Información y licencias de pasajeros". 1640. Ramo 39: Don Juan de Palafox y Mendoza, obispo de la Puebla de los Ángeles y criados que se expresan.

nọ 36 Pedro García Ferrer, natural de la villa de Alcoriza, diócesis de Zara. goza, de edad de 40 años; barbirrubio, con una señal de herida en el rostro debajo de la boca.

nọ 37 Diego Burclab (sic), flamenco natural de Brabante, diócesis de Amberes, de edad de 18 años, la barba hendida, blanco y bajo y abultado de rostro; concédesele licencia en la cédula de Su Majestad.

(al final) Certifico que todos los contenidos en esta memoria van conmigo y son mis criados y ninguno de ellos es de los prohibidos de pasar a las Indias, excepto Diego Bruclab, flamenco, el cual pasa en mi 'servicio con licencia de Su Majestad. Fecho en Sevilla a 15 de marzo de 1640. (Rúbrica:) El Obispo de los Ángeles.

Traslado de [una cédula] de Su Majestad que presentó en esta casa el señor Don Juan de Palafox y Mendoza, obispo de la Puebla de los Ángeles.

Mis presidentes y jueces oficiales de la Casa de la Contratación de Sevilla. Yo os mando que a Don Juan de Palafox y Mendoza, obispo de la iglesia catedral de la provincia de Tlaxcala en al Nueva España, de mi Consejo Real de las Indias, le dejéis pasar a la dicha Nueva España y que pueda llevar 50 criados para su servicio, menos los que pudiere excusar, y entre ellos uno 
flamenco de los países obedientes y un criado casado, llevando este consigo a su mujer, y 12 sacerdotes, a él sin le pedir información alguna y los dichos sacerdotes presentando ante vos sus títulos y dimisiones e informaciones de monibus et vita; y las demás personas presentando asimismo ante vos informaciones hechas en sus tierras ante las justicias de ellas y con aprobación de las mismas justicias de que no son casados ni de los prohibidos a pasar a aquellas partes y de las señas de sus personas; y de estas licencias está declarado que no se debe media anata. Fecha en Madrid a 8 de febrero de 1640 . Yo el Rey Por medio del Rey nuestro señor, D. Gabriel de Ocaña y Alarcón (Al reverso seis rúbricas.) 